\title{
Communication
}

\section{Silicone Oil Decreases Biofilm Formation in a Capacitance-Based Automatic Urine Measurement System}

\author{
Martin Slettengren ${ }^{1,2, * \mathbb{D}}$, Martin Linnros ${ }^{2}$ and Jan van der Linden ${ }^{1,2}$ \\ 1 Division of Perioperative Medicine and Intensive Care, Section of Cardiothoracic Surgery and Anesthesiology, \\ Karolinska University Hospital, SE-171 76 Stockholm, Sweden; jan.vanderlinden@ki.se \\ 2 Department of Molecular Medicine and Surgery, Karolinska Institutet, SE-171 77 Stockholm, Sweden; \\ martin.linnros@sll.se \\ * Correspondence: martin.slettengren@sll.se
}

Citation: Slettengren, M.; Linnros, M.; van der Linden, J. Silicone Oil Decreases Biofilm Formation in a Capacitance-Based Automatic Urine Measurement System. Sensors 2021, 21, 445. https://doi.org/10.3390/ s21020445

Received: 3 December 2020 Accepted: 7 January 2021

Published: 10 January 2021

Publisher's Note: MDPI stays neutral with regard to jurisdictional clai$\mathrm{ms}$ in published maps and institutional affiliations

Copyright: () 2021 by the authors. Licensee MDPI, Basel, Switzerland. This article is an open access article distributed under the terms and conditions of the Creative Commons Attribution (CC BY) license (https:// creativecommons.org/licenses/by/ $4.0 /)$.

\begin{abstract}
Capacitance-based automatic urine measurement is a validated technique already implemented in clinical practice. However, albuminuria and free hemoglobinuria cause progressive biofilm buildup on the capacitance sensors of the urinometers. The aim of this experimental study is to investigate the influence of albumin and free hemoglobin on the capacitance signal of an automatic urinometer with and without the addition of silicone oil. A solution of Ringer's acetate mixed with either albumin or free hemoglobin was run through an automatic urinometer containing either a water-soluble capsule with silicone oil or not. In total, around 500 capacitance measurements were retrieved from the albumin and free hemoglobin group, respectively. The mean increase in capacitance in the albumin $3 \mathrm{~g} / \mathrm{L}$ group was $257 \pm 100 \mathrm{pF}$ without and $105 \pm 30 \mathrm{pF}$ with silicone oil, respectively, during $24 \mathrm{~h}$. After ten hours of recording, differences between the two albumin groups reached statistical significance. For the free hemoglobin groups $(0.01 \mathrm{~g} / \mathrm{L})$, the mean increase in capacitance was $190 \pm 170 \mathrm{pF}$ with silicone oil, and $324 \pm 80 \mathrm{pF}$ without, with a significant difference between the groups after $20 \mathrm{~h}$ and onwards. Coating of the capacitance measurement membrane of the automatic urinometer by albumin or free hemoglobin was significantly decreased by silicone oil, prolonging the functionality of the device.
\end{abstract}

Keywords: silicone oil; electric capacitance; albuminuria; hemoglobinuria; hemolysis; automatic urinometer; biofilm

\section{Introduction}

Most vital parameters in today's intensive care units are recorded automatically, e.g., blood pressure, heart rate, and temperature. Urine output, an essential part of the fluid balance of the body, is, however, still most often recorded manually. This can lead to inaccurate recordings due to human error and/or delay, and also increases the staff's workload. To mitigate these shortcomings, automatic urinometers have been developed, though based on different techniques: droplet-based [1], electromagnetic switch [2], highprecision scale [3], and capacitance [4]. Of these, the last method has proved the most promising and feasible for clinical use $[5,6]$.

Sippi $^{\circledR}$ (Observe Medical, Gothenburg, Sweden) is an automatic urinometer based on capacitance measurements, consisting of a base unit and an attached disposable unit (Figure 1A).

The urinometer is attached to the urinary catheter from where urine flows into the antechamber. In the antechamber, the urine dissolves a capsule containing silicone oil that is transferred with the urine to the measuring chamber located just below. Change in the capacitance between two sensors is used to estimate the urine volume within the measuring chamber. After measurement, the urine departs from the chamber using a siphon technique to a collection bag. This automatic urinometer has previously been validated by our group 
regarding measurement accuracy in both the cardiothoracic [5] and pediatric intensive care units [6].
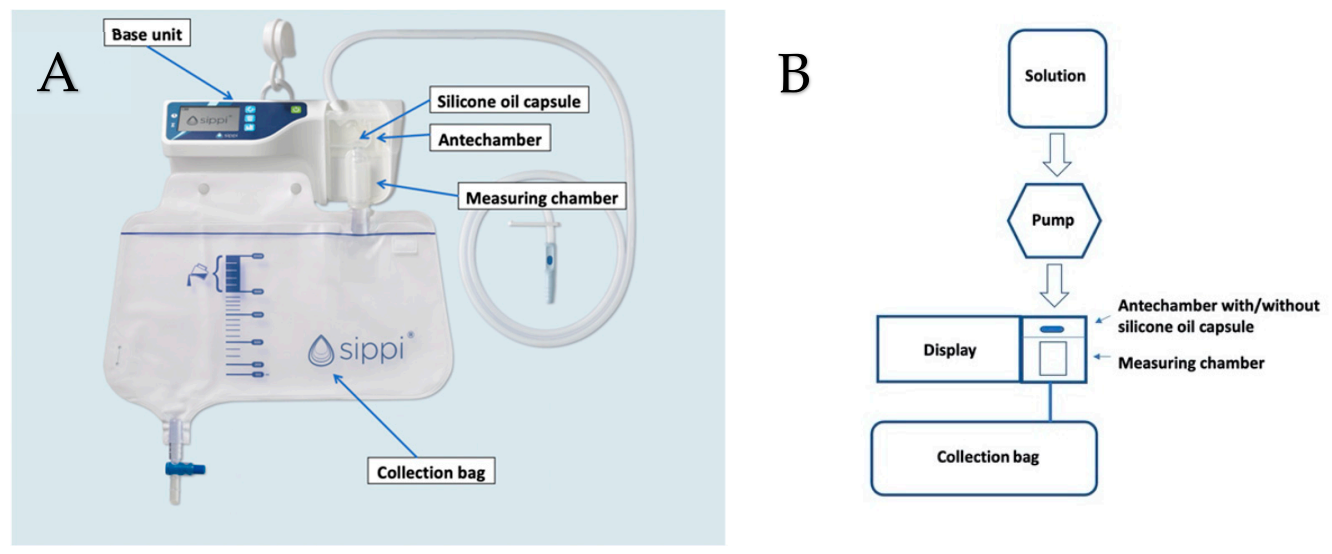

Figure 1. (A) Overview of the evaluated new automatic urinometer (Sippi ${ }^{\circledR}$, Observe Medical, Gothenburg). (B) The experimental setup.

The capacitance of a capacitor is determined by the size and the distance between its plates, and the amount and type of the dielectric. In the automatic urinometer Sippi ${ }^{\circledR}$, the dielectric consists of a column of urine in the measuring chamber. The higher the height of the urine column in the measuring chamber is, the higher the capacitance. By measuring the time it takes to charge and discharge the capacitor, a value is acquired for the capacitance, which relates to the height of the urine column in the measuring chamber. The volume of urine in the measuring chamber can then easily be calculated by the device, based on the change in capacitance. The measurement resolution is $1 \mathrm{~mL}$.

Normally, biofilm is produced by local bacteria sticking to a surface. Methods to reduce biofilm-producing bacteria include surface modifications [7], antimicrobial impregnated surfaces [8], electricity $[9,10]$, and substances to prevent the attachment of bacteria to a surface, such as cellobiose dehydrogenase/amylase [11], hydrogels [12], and silver nanoparticles [13]. Measures may also target established biofilm, e.g., signal interference between bacteria [14], antibiotic-loaded nanoparticles to enhance penetration into biofilm [15], and biofilm dispersion (e.g., Dispersin B) [16]. Lastly, the mechanical removal of biofilm is an option, but it is not easily applied in capacitance sensors. All these options, except mechanical removal, act on local bacteria that produce biofilm. In some cases-in urine, for instance-proteins such as albumin or free hemoglobin may directly form a biofilm over sensor surfaces without the involvement of bacteria. Removal of this type of biofilm is very difficult and, as far as we know, only the mechanical option is available.

A problem when using capacitance measurements to estimate urine volume is that the biofilm coating of the reading membrane will influence the capacitance signal [17], resulting in false readings, or even complete shutdown. Pilot clinical tests of the automatic urinometer Sippi ${ }^{\circledR}$ in patients undergoing cardiac surgery revealed that measurements could not be recorded after $24 \mathrm{~h}$ in some patients who have albuminuria and/or hemoglobinuria, or a urinary tract infection. By adding a water-soluble capsule containing silicone oil to the antechamber of the device, these problems seemed to be prevented clinically, and the device could function for the recommended period of use of the disposable unit (1 week).

The aim of this study is to investigate whether albumin or free hemoglobin $(\mathrm{fHb})$, common in the urine of patients following cardiac surgery, could influence the capacitance signal of the automatic urinometer, and whether this could be prevented by adding silicone oil to the measuring chamber of the device. 


\section{Materials and Methods}

\subsection{Experimental Setup}

This was a prospective cohort, in vitro study investigating the effect of silicone oil on biofilm formation of albumin and $\mathrm{fHb}$, each diluted in a separate solution. The studied solution was stored in a $2500 \mathrm{~mL}$ container with an outgoing tube, which passed through a peristaltic pump (WELCO WPX1-P3/328; WELCO Co., Ltd., Tokyo, Japan), powered by an SPS 8041 (Manson Engineering Industrials Ltd., Hong Kong, China) with a default of 4.5 volts. The outgoing tube was then connected to the ingoing tube of the Sippi ${ }^{\circledR}$ device. To prevent a vacuum, air was let into the container through a small hole, created with an $18 \mathrm{G}$ needle. The solution was thus run through the antechamber of the Sippi ${ }^{\circledR}$, and then into its disposable collection bag (Figure 1B).

The circuit was assembled either with or without a silicone oil capsule in the antechamber. The silicone oil capsule was dissolved when the studied solution entered the antechamber, whereby the silicone oil was transferred by the solution to the measuring chamber, where it adhered to the polypropylene plastic walls [18]. Alternatively, the silicone oil capsule was removed through a hole created by a soldering iron in the front of the antechamber. Thereafter, the hole was sealed with a 3M tape designed for plastic surfaces. Every $24 \mathrm{~h}$, a new solution was added to the container and the collection bag was emptied.

We used a medium-viscosity silicone oil (viscosity $350 \mathrm{~mm}^{2} / \mathrm{s}$ at $25^{\circ} \mathrm{C}$ ) (Silbione ${ }^{\circledR}$, oils 70047, V350, Elkem, Oslo, Norway). This oil is a linear polydimethylsiloxane, chemically inert, heat-resistant, nontoxic, and has a low surface tension [19].

\subsection{Albumin Solution}

The first part of the study investigated the effect of an albumin solution on capacitance measurements with and without silicone oil released from a capsule. Sixty milliliters of albumin (Alburex ${ }^{\circledR} 50 \mathrm{~g} / \mathrm{L}$, CSL Behring AB, Danderyd, Sweden) was diluted in $960 \mathrm{~mL}$ of Ringer's acetate (Baxter International Inc, Deerfield, MA, USA), giving a concentration of $3 \mathrm{~g}$ of albumin/L. A new mixture with the same concentration, for each Sippi ${ }^{\circledR}$-peristaltic pump system, was produced for every $24 \mathrm{~h}$ measurement. The mixture was stored in a $2500 \mathrm{~mL}$ container as described above. The peristaltic pump was calibrated to achieve a flow rate of approximately $42 \mathrm{~mL} / \mathrm{h}$, resulting in an estimated total protein concentration of $3 \mathrm{~g} / 24 \mathrm{~h}$. The albumin-Ringer's acetate solution was conducted with two parallel groups: 20 times with silicone oil and 20 times without. Moreover, two additional experiments with a lower albumin concentration, $0.3 \mathrm{~g} / \mathrm{L}$ and $1.0 \mathrm{~g} / \mathrm{L}$, respectively, were conducted.

\subsection{Free Hemoglobin Solution}

The second part of the study investigated the effect of $\mathrm{fHb}$ on capacitance measurement with and without silicone oil released from a capsule. $\mathrm{fHb}$ was acquired from blood remaining in syringes after routine arterial blood gas analysis in patients. Thirty-nine separate syringes were used. The residual blood from the syringes was centrifuged with a Sigma 1A (Axel Johnson Instruments AB, Stockholm, Sweden) at 3200 rotations per minute (RPM), for $10 \mathrm{~min}$. The bottom layer, consisting of erythrocytes, was then extracted using a RAININ Pipet-lite SL1000 dropper (Rainin Instruments LLC, Oakland, CA, USA). In order to achieve lysis through osmosis, the erythrocyte concentrate was mixed with sterile water to give a volume of $10 \mathrm{~mL}$. The $\mathrm{fHb}$ concentration was then measured with a HEMOCUE ${ }^{\circledR}$ PLASMA/LOW Hb $201+$ Hemoglobin spectrophotometer (HemoCue America, Brea, CA, USA). The $10 \mathrm{~mL}$ of $\mathrm{fHb}$ mixture was added to $990 \mathrm{~mL}$ of Ringer's acetate and stored in $2500 \mathrm{~mL}$ containers as described above. Every $24 \mathrm{~h}$, a new mixture, for each Sippi ${ }^{\circledR}$-peristaltic pump system, was produced and used in the same way as before, with continuous capacitance measurements for $24 \mathrm{~h}$. The $\mathrm{fHb}$ solution experiments were conducted 20 times with silicone oil and 20 times without. 


\subsection{Extraction of Data from the Automatic Urinometer}

Measurements of capacitance in the measuring chamber were conducted 60 times/h, i.e., 1440 times $/ 24 \mathrm{~h}$, and data were stored on a removable micro-SD memory card inside the device. Analysis of the data was carried out after each $24 \mathrm{~h}$ run. In order to reach the micro-SD memory card, the batteries of the Sippi ${ }^{\circledR}$ base unit were removed with a SANDVIK 7890 nippers (SNA Europe, Enköping, Sweden). The card was then inserted in a micro-SD card reader and the data were transferred to an Excel file. Every $24 \mathrm{~h}$, a new disposable set was used, except for the $2500 \mathrm{~mL}$ container, which was reused after cleaning in a GETINGE 600 series industrial washer (Getinge Group, Gothenburg, Sweden). Before new tubes and disposable sets were connected, the hardware unit was reset, and the WELCO pumps and the SPS 8041 power unit were calibrated so that all used pumps operated at the same speed at 4.5 volts. The containers were refilled with new solution, and the pumps were restarted. Careful initial monitoring of the circuit ensured that it worked as expected and that the fluid dissolved the silicone oil capsule correctly.

\subsection{Analysis of Capacitance Data}

The Sippi ${ }^{\circledR}$ registers capacitance twice every second. Capacitance is the ability to store electrical charge and is affected by the height of urine in the measuring chamber, which can then be converted by the device to a volume. A mean of the two measurements is logged to the micro-SD card of the device once every minute. From these raw data (1440 measurements/day), the lowest value from every $60 \mathrm{~min}$ period was extracted and stored in an Excel file, resulting in 24 measurements from every pump system per day. Twenty runs with two parallel systems (one with and one without a silicon capsule) yielded a total of 480 measurements for each group $(24 \times 20)$. Each stored capacitance value was the lowest starting point of every hourly capacitance measurement and represented, when compared with the initial starting point, the increase in capacitance due to biofilm coating of the inner surface of the measuring chamber by albumin or $\mathrm{fHb}$. When the baseline value goes up, it indicates the growth of biofilm coating. Eventually, it would reach a critical point at which the measurement of urine is no longer possible.

\subsection{Statistical Analysis}

Mean and standard deviation (SD) were used for descriptive purposes. Group differences were assessed using the independent samples' $t$-test, as the data were normally distributed. A $p$-value of less than 0.05 was considered significant. All $p$-values were two-sided. Statistical analysis was performed using the IBM SPSS Statistics for Macintosh, version 22.0 (IBM Corp., Armonk, NY, USA).

\subsection{Ethical Considerations}

Ethical permission was obtained for this study from the regional ethical review board in Stockholm (approval no. 2015-66632 and 2015/2351-32).

\section{Results}

\subsection{Effect on Capacitance Measurement by Albumin}

In total, 477 measurements without, and 472 measurements with silicone oil, respectively, were analyzed. During the 24th h, 29 measurements were excluded as readings were too few to extract a reliable average. Moreover, in a few cases, the liquid container was emptied and the pump ran dry before the end of the $24 \mathrm{~h}$ measurement period. The maximum capacitance value was 790 picofarads $(\mathrm{pF})$ in the group without, and $633 \mathrm{pF}$ in the group with silicone oil, respectively. The mean increase in capacitance was $257 \pm 100 \mathrm{pF}$ in the group without, and $105 \pm 30 \mathrm{pF}$ in the group with silicone oil, respectively. After ten hours of recording, the difference between the groups reached statistical significance $(p=0.011$, see Supplement Table S1).

The buildup of albumin coating over time is summarized in Figure 2, shown as the mean of the minimum capacitance, with and without silicone oil. The additional 
experiments, with $0.3 \mathrm{~g} / \mathrm{L}$ and $1.0 \mathrm{~g} / \mathrm{L}$ albumin solution with 379 and 190 measurements, respectively, did not show significant differences in capacitance with and without silicone oil during the $23 \mathrm{~h}$ time frame (data not shown).
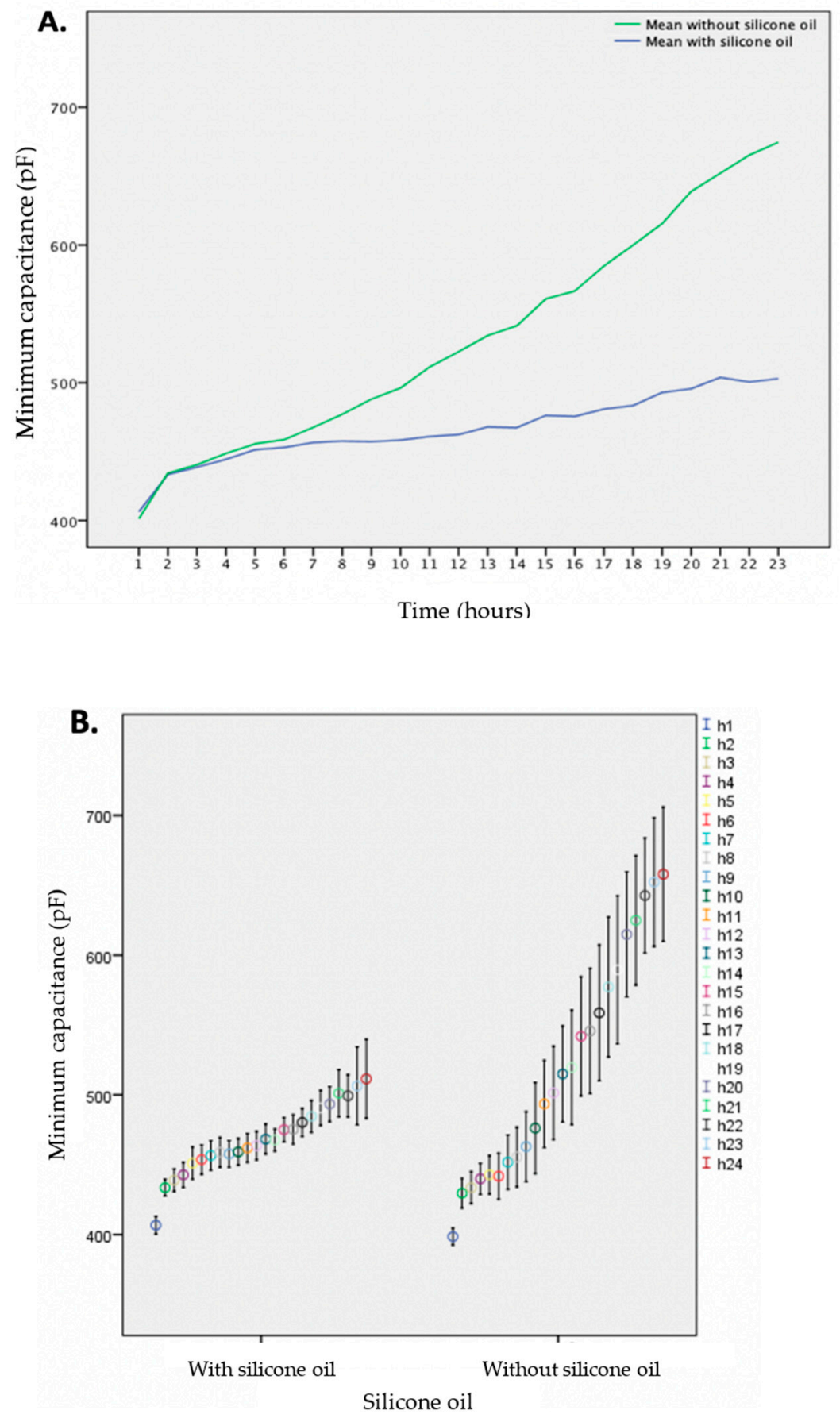

Figure 2. (A) Mean capacitance measurements caused by an albumin solution during $23 \mathrm{~h}$ of coating for devices without (green) and with (blue) the addition of silicone oil. (B) Median, maximum, and minimum capacitance values caused by an albumin solution for each hour with and without the addition of silicone oil.

\subsection{Effect on Capacitance Measurements by Free Hemoglobin}

In total, 484 measurements without, and 414 with silicone oil, were compared. The mean concentration of $\mathrm{fHb}$ in the prepared mixtures was $0.0141 \mathrm{~g} / \mathrm{L}$, ranging from $0.0056 \mathrm{~g} / \mathrm{L}$ to $0.0173 \mathrm{~g} / \mathrm{L}$. The mean concentration in the group with silicone oil was $0.0113 \mathrm{~g} / \mathrm{L}$, and 
$0.0125 \mathrm{~g} / \mathrm{L}$ in the group without. The mean increase in capacitance was $190 \pm 170 \mathrm{pF}$ with silicone oil, and $324 \pm 80 \mathrm{pF}$ without. A significant difference between the groups was seen after $20 \mathrm{~h}$ and onwards ( $p=0.031$, see Supplemental Table S2).

The last two hours of measurements were excluded from the analysis as the readings during the 23rd and 24th $\mathrm{h}$ did not result in a sufficient number of readings to test for differences. Figure 3 depicts the mean increase in capacitance due to the buildup of $\mathrm{fHb}$ coating over time, in the group with and without silicone oil, respectively.
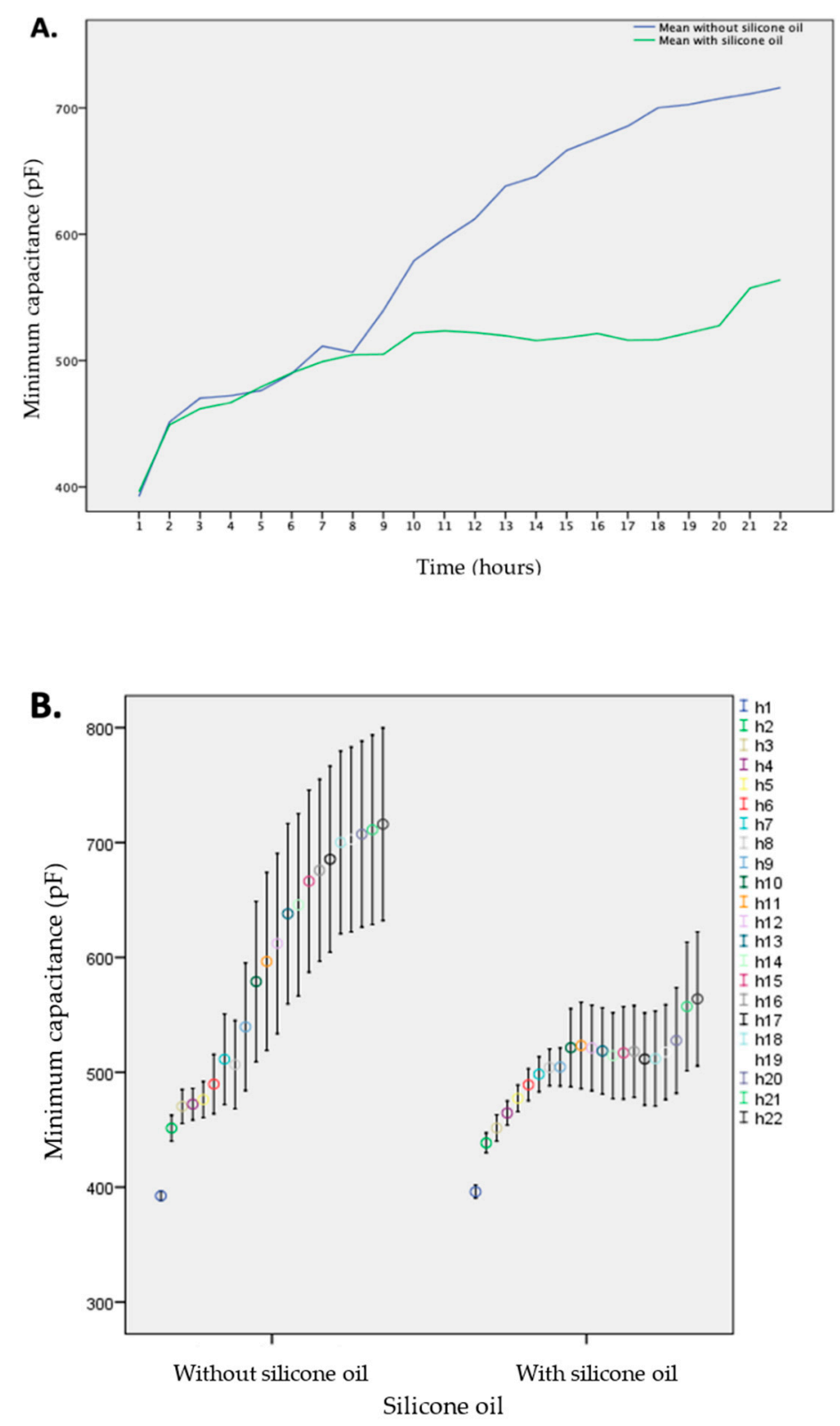

Figure 3. (A) Mean capacitance measurements caused by a free hemoglobin solution during $22 \mathrm{~h}$ of coating for devices without (blue) and with (green) the addition of silicone oil. (B) Median, maximum, and minimum capacitance values caused by a free hemoglobin solution for each hour with and without the addition of silicone oil.

\section{Discussion}

Silicone oil significantly reduces the capacitance increase caused by the coating of albumin or $\mathrm{fHb}$ solutions on the measuring membrane of the automatic urinometer, thereby prolonging its functionality. Capacitance-based measurement is a validated technique to continuously and automatically estimate urine volume output [4-6]. Clinically, however, 
we found the technique susceptible to biofilm coating by $\mathrm{fHb}$ and albumin, in the urine of several patients undergoing cardiac surgery. Therefore, we investigated a new version of the automatic urinometer Sippi ${ }^{\circledR}$ device that contained silicone oil in a water-soluble capsule in its antechamber.

Normally, healthy kidneys only filter very small amounts of protein into the urine, as almost all protein molecules are too large to be filtered through glomeruli. Proteinuria may be due to diseases of the glomeruli, e.g., glomerulonephritis or diabetes mellitus, urinary infection, congestive heart failure, surgery, or genetic differences in the glomerular endothelial function [20]. It is a known independent risk factor for acute renal injury [21]. In patients undergoing cardiac surgery, both preoperative [22] and postoperative [23] albuminuria can predict which patients have an increased risk of developing AKI during their hospital stay. In a large clinical study involving 1200 patients undergoing coronary surgery [23], 80\% of patients had early postoperative albumin levels in urine of $0.05 \mathrm{~g} / \mathrm{L}$ or lower. Thus, our studied albumin solution of $3 \mathrm{~g} / \mathrm{L}$ had a significantly higher concentration than the concentration of albumin in urine found postoperatively in at least $80 \%$ of patients undergoing conventional cardiac surgery, implying that the beneficial effect of silicone oil should apply to the vast majority of conventional postoperative cardiac surgery patients.

Furthermore, early postoperative albuminuria improved the prediction of acute kidney injury to the greatest degree (clinical model area under the curve, $0.75 ; 0.81$ with albuminuria) [23].

Hemolysis occurs during extended operations on cardiopulmonary bypass (CPB) or extracorporeal membrane oxygenation (ECMO). This may be due to mechanical forces, e.g., shear stress, hypothermia, turbulent flow, excessive pump speed, cavitation, or decreased oncotic pressure and clot formation, resulting in complete lysis or variable degrees of damage to red blood cells [24-26]. Excess fHb in blood is filtered by the kidneys, which excrete it into the urine, giving it a dark red color. Hemoglobinuria may lead to acute tubular necrosis, acute renal failure, and need for dialysis. In a study by Heijmans et al. [27], patients undergoing extended periods of $\mathrm{CPB}$ (valve + coronary surgery) had higher levels of plasma $\mathrm{fHb}$ than those undergoing shorter periods (coronary surgery) during $\mathrm{CPB}$ and the first postoperative hours. In contrast, patients undergoing off-pump coronary surgery did not have increased levels of $\mathrm{fHb}$ in plasma. Patients with AKI (13.4\%) exhibited significantly higher $\mathrm{fHb}$ already during surgery, compared with patients without AKI.

Both the solution containing albumin $(3 \mathrm{~g} / \mathrm{L})$, and that containing $\mathrm{fHb}$, significantly increased the capacitance measurement in the automatic urinometer, perhaps by changing the properties of the dielectric between the plates that determine the measured capacitance values, and thus the estimated urine volume. One theory is that the electrical quantities change depending on the excitation quantities, which in this study corresponds to the electrical capacity dependence on the albumin concentration and on the free hemoglobin concentration in the urine [28]. Importantly, the urinometer will initially, despite the increased biofilm coating of the measurement membrane, quantify the urine volume correctly until a certain cut-off value is reached, whereupon the urinometer will shut down prematurely. The rises in capacitance were clearly and significantly lower when the urinometers contained silicone oil during the $23 \mathrm{~h}$ study period, partially preventing biofilm formation in the measuring chamber.

The siphon cassette of the studied automatic urinometer, consisting of the antechamber and the measuring chamber, is made up of polypropylene plastic, which is inherently hydrophobic and oleophilic [29]. Due to the nonpolar and hydrophobic properties attributed to polypropylene, silicone oil will accumulate on the surface of polypropylene. Based on the chemical structure and an initial pilot study using Raman microscopy (unpublished data), some amount of the hydrophobic oil will attach to the polypropylene plastic surface, in the form of minute droplets, and in doing so, exert the long-lasting, clinically observed effect, despite surfaces being intermittently exposed to air between each emptying of the measuring chamber. 
The clinical consequence of the addition of silicone oil is that urine volume measurements with this capacitance-based automatic urinometer can be reliable for longer periods, before the disposable part with the measuring chamber needs to be replaced in patients who have hemoglobinuria and/or albuminuria, e.g., early postoperatively after cardiac surgery with $\mathrm{CPB}$, and in patients with diabetes mellitus and renal dysfunction. Indeed, our initial clinical observation of failed measurements early after cardiac surgery was not seen in any patients after the inclusion of the water-soluble capsule containing silicone oil, whereupon the urinometer was still functioning 7 days later, which is the recommended period of use of the disposable unit. To our knowledge, this is the first study indicating at least partial protection of an albumin and $\mathrm{fHb}$ biofilm, respectively, on plastic surfaces with use of silicone oil.

This study has a few limitations. First, we used Ringer's acetate instead of real urine. We could have used more complicated formulas for artificial urine [30], but we regarded Ringer's acetate an appropriate, cheap, and easily available solution to mix with albumin and $\mathrm{fHb}$. In contrast, it would have been complicated and costly to produce large volumes of sterile artificial urine. Another alternative would have been to use human urine. However, that would also have been complicated considering the large volume needed (approximately $80 \mathrm{~L}$ ), the great interindividual variation in electrolyte composition and $\mathrm{pH}$, as well as keeping these large volumes sterile. Moreover, other studies have used similar solutions as a replacement for human urine, e.g., Rasmussen et al., investigated ascending infections using $0.9 \%$ saline [31]. Second, if our experiments had lasted more than $24 \mathrm{~h}$, we could have seen significant effects with the 0.3 and $1.0 \mathrm{~g} / \mathrm{L}$ albumin solution, respectively. Third, the concentration of $\mathrm{fHb}$ differed slightly between each run. However, the mean difference in concentration was very similar between both groups and should consequently only marginally have influenced the results. Interestingly, the $\mathrm{fHb}$ concentration in urine in patients with discolored urine in the first hours after cardiac surgery with CPB usually vary between 0.1 and $5 \mathrm{~g} / \mathrm{L}$ in our cardiothoracic intensive care unit, after which it usually drops. Thus, in our study we used an $\mathrm{fHb}$ concentration that was approximately $10 \%$ of the real values at most. On the other hand, since the introduction of the built-in silicon capsule in the disposable part of the Sippi ${ }^{\circledR}$ device, we have not experienced malfunctioning measurements in our clinical routine. Fourth, the study was not randomized or blinded, but as data measurements were automatic this should not have influenced the results.

In summary, coating by albumin or $\mathrm{fHb}$ of the capacitance measurement membrane of an automatic urinometer can be significantly decreased by integrating a dissolvable capsule of silicone oil in the antechamber of the device, and in doing so, prolong its functionality.

Supplementary Materials: The following are available online at https:/ / www.mdpi.com/1424-8220/ 21/2/445/s1, Table S1: Capacitance parameters and change over $23 \mathrm{~h}$ with albumin solution $(3 \mathrm{~g} / \mathrm{L})$, Table S2: Capacitance parameters and change over $22 \mathrm{~h}$ with free hemoglobin solution $(0.01 \mathrm{~g} / \mathrm{L})$.

Author Contributions: Conceptualization, J.v.d.L. and M.S.; methodology, J.v.d.L. and M.S.; software, M.L. and M.S.; validation, M.L., M.S., and J.v.d.L.; formal analysis, M.L., M.S., and J.v.d.L.; investigation, M.L. and M.S.; resources, M.L., M.S., and J.v.d.L.; data curation, M.L. and M.S.; writing—original draft preparation, J.v.d.L. and M.S.; writing-review and editing, J.v.d.L. and M.S.; visualization, M.L. and M.S.; supervision, J.v.d.L.; project administration, J.v.d.L.; funding acquisition, J.v.d.L. All authors have read and agreed to the published version of the manuscript.

Funding: This work was supported by grants from Karolinska Institutet (JvdL). Grant nr: N/A.

Institutional Review Board Statement: The study was conducted according to the guidelines of the Declaration of Helsinki, and approved by the regional ethical review board in Stockholm (approval no. 2015-66632 approved on 13.04.2015 and 2015/2351-32 approved on 29.12.2015).

Informed Consent Statement: Not applicable.

Data Availability Statement: The data presented in this study are available in Supplemental Tables S1 and S2. 
Acknowledgments: Observe Medical supplied the automatic urinometers and silicone oil used in this study free of charge, but had no influence on the design of the study, data interpretation, writing of the manuscript, decision to submit, or where to submit the manuscript for publication.

Conflicts of Interest: The authors declare no conflict of interest. Observe Medical supplied the silicone oil used in this study free of charge, but had no impact on the design of the study, the data interpretation, the writing of the manuscript, the decision to submit, or where to submit the manuscript for publication.

\section{References}

1. Hersch, M.; Einav, S.; Izbicki, G. Accuracy and ease of use of a novel electronic urine output monitoring device compared with standard manual urinometer in the intensive care unit. J. Crit. Care 2009, 24, 629.e13-629.e17. [CrossRef] [PubMed]

2. Otero, A.; Palacios, F.; Akinfiev, T.; Apalkov, A. A Low Cost Device for Monitoring the Urine Output of Critical Care Patients. Sensors 2010, 10, 10714-10732. [CrossRef] [PubMed]

3. Otero, A.; Palacios, F.; Akinfiev, T.; Fernandez, R. A device for automatically measuring and supervising the critical care pa-tient's urine output. Sensors 2010, 10, 934-951. [CrossRef] [PubMed]

4. Otero, A.; Fernández, R.; Apalkov, A.; Armada, M. An Automatic Critical Care Urine Meter. Sensors 2012, 12, 13109-13125. [CrossRef] [PubMed]

5. Eklund, A.; Slettengren, M.; van der Linden, J. Performance and user evaluation of a novel capacitance-based automatic uri-nometer compared with a manual standard urinometer after elective cardiac surgery. Crit. Care 2015, 2, 173. [CrossRef]

6. Slettengren, M.; Wetterfall, H.; Eklund, A.; Van Der Linden, J. A Pilot Evaluation of a Capacitance-Based Automatic Urinometer in a Pediatric Intensive Care Setting. Pediatr. Crit. Care Med. 2019, 20, 769-772. [CrossRef] [PubMed]

7. Chouirfa, H.; Bouloussa, H.; Migonney, V.; Falentin-Daudré, C. Review of titanium surface modification techniques and coat-ings for antibacterial applications. Acta Biomater. 2019, 2, 37-54. [CrossRef]

8. Fisher, L.E.; Hook, A.L.; Ashraf, W.; Yousef, A.; Barrett, D.A.; Scurr, D.J.; Bayston, R. Biomaterial modification of urinary catheters with an-timicrobials to give long-term broadspectrum antibiofilm activity. J. Control Release 2015, 2, 57-64. [CrossRef]

9. Del Pozo, J.L.; Rouse, M.S.; Euba, G.; Greenwood-Quaintance, K.E.; Mandrekar, J.N.; Steckelberg, J.M.; Patel, R. Prevention of Staphylo-coccus epidermidis biofilm formation using electrical current. J. Appl. Biomater. Funct. Mater. 2014, $12,81-83$.

10. del Pozo, J.L.; Rouse, M.S.; Mandrekar, J.N.; Sampedro, M.F.; Steckelberg, J.M.; Patel, R. Effect of electrical current on the activities of antimicrobial agents against Pseudomonas aeruginosa, Staphylococcus aureus, and Staphylococcus epidermidis biofilms. Antimicrob. Agents Chemother. 2009, 53, 35-40. [CrossRef]

11. Thallinger, B.; Argirova, M.; Lesseva, M.; Ludwig, R.; Sygmund, C.; Schlick, A.; Guebitz, G.M. Preventing microbial colonisation of cathe-ters: Antimicrobial and antibiofilm activities of cellobiose dehydrogenase. Int. J. Antimicrob. Agents 2014, 44, 402-408. [CrossRef] [PubMed]

12. Kolewe, K.W.; Peyton, S.R.; Schiffman, J.D. Fewer Bacteria Adhere to Softer Hydrogels. ACS Appl. Mater. Interfaces 2015, 7, 19562-19569. [CrossRef]

13. Heidari Zare, H.; Juhart, V.; Vass, A.; Franz, G.; Jocham, D. Efficacy of silver/hydrophilic poly(p-xylylene) on preventing bacteri-al growth and biofilm formation in urinary catheters. Biointerphases 2017, 12, 011001. [CrossRef] [PubMed]

14. Beloin, C.; Renard, S.; Ghigo, J.-M.; Lebeaux, D. Novel approaches to combat bacterial biofilms. Curr. Opin. Pharmacol. 2014, 18, 61-68. [CrossRef] [PubMed]

15. Cheow, W.S.; Hadinoto, K. Antibiotic Polymeric Nanoparticles for Biofilm-Associated Infection Therapy. Comput. Biol. 2014, 1147, 227-238. [CrossRef]

16. Kerrigan, J.E.; Ragunath, C.; Kandra, L.; Gyémánt, G.; Lipták, A.; Jánossy, L.; Ramasubbu, N. Modeling and biochemical analysis of the activi-ty of antibiofilm agent Dispersin, B. Acta Biol. Hung. 2008, 59, 439-451. [CrossRef] [PubMed]

17. Maurício, R.; Dias, C.; Santana, F. Monitoring Biofilm Thickness Using A Non-Destructive, On-Line, Electrical Capacitance Technique. Environ. Monit. Assess. 2006, 119, 599-607. [CrossRef]

18. Slettengren, M.; Mohanty, S.; Kamolvit, W.; Van Der Linden, J.; Brauner, A. Making medical devices safer: Impact of plastic and silicone oil on microbial biofilm formation. J. Hosp. Infect. 2020, 106, 155-162. [CrossRef]

19. Silbione Oils 70047 V100 and V350; Technical Data Sheet n SIL 113613 July 2011. Available online: www.bluestarsilicones.com (accessed on 25 September 2020).

20. Dobre, D.; Nimade, S.; De Zeeuw, D. Albuminuria in heart failure: What do we really know? Curr. Opin. Cardiol. 2009, 24, 148-154. [CrossRef]

21. James, M.T.; Grams, M.E.; Woodward, M.; Elley, C.R.; Green, J.A.; Wheeler, D.C.; Ballew, S.H. A Meta-analysis of the Association of Estimat-ed GFR, Albuminuria, Diabetes Mellitus, and Hypertension with Acute Kidney Injury. Am. J. Kidney Dis. 2015, 66, 602-612. [CrossRef]

22. Huang, T.-M.; Wu, V.-C.; Young, G.-H.; Lin, Y.-F.; Shiao, C.-C.; Wu, P.-C.; Li, W.-Y.; Yu, H.-Y.; Hu, F.-C.; Lin, J.-W.; et al. Preoperative Proteinuria Predicts Adverse Renal Outcomes after Coronary Artery Bypass Grafting. J. Am. Soc. Nephrol. 2010, 22, 156-163. [CrossRef] [PubMed] 
23. Molnar, A.O.; Parikh, C.R.; Sint, K.; Coca, S.G.; Koyner, J.; Patel, U.D.; Butrymowicz, I.; Shlipak, M.; Garg, A.X. Association of Postoperative Proteinuria with AKI after Cardiac Surgery among Patients at High Risk. Clin. J. Am. Soc. Nephrol. 2012, 7, 1749-1760. [CrossRef] [PubMed]

24. Kameneva, M.V.; Undar, A.; Antaki, J.F.; Watach, M.J.; Calhoon, J.H.; Borovetz, H.S. Decrease in red blood cell deformability caused by hypothermia, hemodilution, and mechanical stress: Factors related to cardiopulmonary bypass. ASAIO J. 1999, 45, 307-310. [CrossRef] [PubMed]

25. Vercaemst, L. Hemolysis in Cardiac Surgery Patients Undergoing Cardiopulmonary Bypass: A Review in Search of a Treatment Algorithm. J. Extra-Corporeal Technol. 2008, 40, 257-267.

26. Toomasian, J.M.; Bartlett, R.H. Hemolysis and ECMO pumps in the 21st Century. Perfusion 2010, 26, 5-6. [CrossRef]

27. Vermeulen Windsant, I.C.; de Wit, N.C.; Sertorio, J.T.; van Bijnen, A.A.; Ganushchak, Y.M.; Heijmans, J.H.; Buurman, W.A. Hemolysis during cardiac surgery is associated with increased intravascular nitric oxide consumption and perioperative kidney and intestinal tissue damage. Front. Physiol. 2014, 2, 340. [CrossRef]

28. Bica, I.; Anitas, E.M. Magneto-active fabrics based on glucose and carbonyl iron: Effects of glucose crystallization kinetics and magnetic field on the electrical conductivity. J. Magn. Magn. Mater. 2020, 495, 165883. [CrossRef]

29. Staff, C.M. Everything You Need to Know about Polypropylene (PP) Plastic 2016. Available online: https://www. creativemechanisms.com/blog/all-about-polypropylene-pp-plastic (accessed on 20 October 2020).

30. Sarigul, N.; Korkmaz, F.; Kurultak, I. A New Artificial Urine Protocol to Better Imitate Human Urine. Sci. Rep. 2019, 9, 1-11. [CrossRef]

31. Rasmussen, A.; Frimodt-Møller, N.; Espersen, F.; Roed, M.; Frimodt-Møller, C. Retrograde contamination and practical handling of urine-meters: A comparison of three systems for the measurement of hourly diuresis in an experimental blad-der-drainage model and in clinical use. Br. J. Urol. 1996, 78, 187-191. [CrossRef] 